Brit. J. industr. Med., 1951, 8, 265.

\title{
THE HAZARDS OF ROPE MAKING
}

\author{
BY \\ JAMES A. SMILEY \\ From Belfast Ropework; Ltd.
}

The first rope makers to leave concrete evidence of their work were the Egyptians. We know from contemporary relics that about 3000 B.C. sails for ships in the Mediterranean Sea were rigged with rope which had to be spliced and run smoothly through cleats. One of the earliest representations of actual rope making is on a tomb of the Fifth Dynasty at Thebes, which shows a man and a boy with the inscription: "Twisting ropes of boat building". There are numerous references to ropes and rope making in classical literature in the works of Homer, Herodotus, Pliny, and others, and at least three references to spinning and to thread can be found in the books of Genesis and Exodus. A more modern author, Longfellow, in his poem "The Rope Makers" has given a graphic description of the ropewalk, a picture of processes which are much the same to this day. Indeed many of our workers who served during the late war in the East, and in particular one rope maker who watched the primitive methods of peasants in Cyprus, recognized the fundamental identity of the method of manufacture.

\section{Preparation and Spinning}

A modern rope works produces not only ropes with circumferences varying from $\frac{1}{2}$ in. to 28 in., but also threads, twines, and cords of an infinite variety. It has been estimated that this rope works has manufactured over half a million different types of products including ropes for mountaineering, cords for reins, lines for anglers, ropes for gallows, cords for the drums of regimental bands, log-lines, ropes for whale harpooning, plaited cords for window blinds, binder-twine for harvesters, and a host of other products.

In Great Britain over 1,500 tons of raw materials, mostly hemp, are used each week by rope works. The materials come from all over the world : the hard fibres of Manila hemp from the Philippines and Borneo, the New Zealand hemp from St. Helena, and Sisal hemp from East Africa and Sumatra all with different qualities, but all with fibres up to
$10 \mathrm{ft}$. long. These fibres are used in the manufacture of strong heavy ropes and cables. The soft fibres of hemp and jute come mainly from Italy, India, and Chile, and are used in the main for the making of twines and cords. Some of these fibres average 8 to 9 feet in length. Flax is also used where strength and lightness of weight are required at the same time, and in recent years artificial fibres such as fibro and nylon have been increasingly used. The fibres come in bales weighing 250 to $300 \mathrm{lb}$., and these are stacked in bays up to $15 \mathrm{ft}$. high. Until modern lifting gear became available, accidents, often very severe, were common. Occasionally serious crushing accidents, or more rarely fractures of the legs, still occur, but these are being gradually eliminated. The bales are composed of bundles or " heads" which have to be separated by hand before the mechanical process begins. The separation of these "heads" stirs up an enormous quantity of dust. In the case of Indian hemp it was estimated some years ago that the loss of weight per bale was about $22 \mathrm{lb}$., almost $10 \%$. Not all of this dust is vegetable. Indeed, on analysis, most of it was found to be soil and sand.

When hemp is harvested, the Indian peasant pulls the ripened plant, and ties each handful into a " head" by knotting it into a fairly tight loop at the end. He is paid by the number of "heads" he harvests. The "heads" are then retted in water, and after that they are laid out to dry before baling is done. As water is scarce, the retting tanks soon have insufficient water and become muddy. The mud adheres to the fibres when they are drying, and this, of course, increases the weight and bulk of the bale. There are two ways of dealing with the knotted heads. Either the head can be cut off, involving the loss of a substantial weight of raw material, and, what is more important, the shortening of the length of fibre, or the hemp could be harvested without being tied in bundles. This latter method would have had many advantages. In 1938 this method was the subject of a correspondence with the Board of Trade, the India 


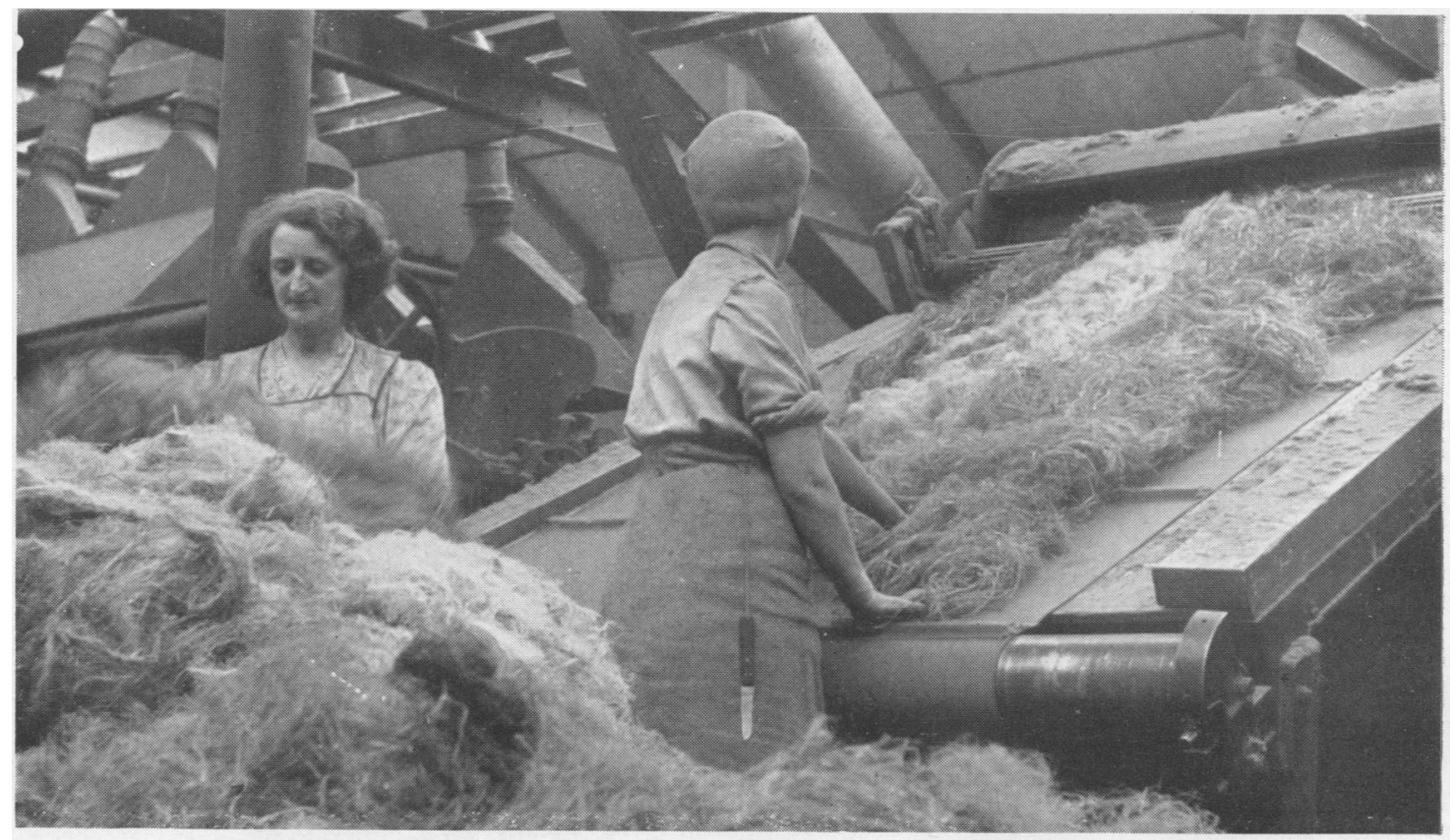

FIG. 1.-The woman on the left is teasing fibre which is being thrown on the " card" by the woman on the right. The jobs are interchangeable. Note the knife hanging from the waist, used for opening bales; also dust deposits on the sides of the machine and hoods of extraction plant.

Office, and our local agents in India, but although a better price was offered for unknotted hemp, it was impossible to effect a change in the harvesting methods which have been carried on from prehistoric times. Thus the control of this dust hazard involves not only the usual methods of suppression and extraction, but the institution of a good system of irrigation, and a modification of traditional harvesting methods in a country thousands of miles away.

After the hemp has been unpacked and loosened, it is fed to machines which have two sets of chains fitted with bars carrying steel pins known as " hackle pins" (Fig. 1). The first chain carries the fibre to the second which, as it is travelling faster, has the effect of combing and straightening out the fibre, cleaning it, and forming it into continuous ribbons or "slivers". A similar process is repeated several times, and the fibre is then drawn and finally twisted into yarn on spinning machines which also wind the yarn on bobbins ready for the making-up departments.

\section{Respiratory Hazard}

In the preparing room where the initial processes are carried out an immense amount of dust can be generated. In the recent past about one in 10 of all workers, mostly women, who worked in this room could expect within 30 years to develop a condition which was known to them as "pousse", a degraded derivative of the French word meaning "dust". (The linen and textiles trades were introduced to Ireland by the Hugenots.) The condition when fully developed seems to differ in no way from chronic bronchitis with emphysema. On taking up employment as a youngster, coughing on entering the dusty atmosphere is usual. Soon the worker seems to develop a tolerance, and the cough ceases. Occasionally, a young person within a week not only coughs but develops a " streaming cold ", and the eyes as well as the nose are affected. (This is a familial trade, and there are many examples of three generations of a family working side by side.) A tradition has grown up amongst the workers that such a young person should leave immediately, as she is liable eventually to develop " pousse".

Further symptoms seldom develop under the age of 55 years. Cough in those affected then begins with the production of thick, tenacious mucus, and after a bout the patient is sufficiently dyspnoeic to simulate an attack of asthma. The victims usually feel better during the summer months and often at the weekend, but with the onset of cold weather or a return to the dusty atmosphere symptoms are exacerbated. In the 
course of years, cyanosis gradually develops, and with it is associated polycythaemia. Wheezing is common but loss of weight in these women, most of whom are stout, is not as marked as might be expected, presumably because their dyspnoea enforces rest. Examination usually reveals the large, barrel-shaped thorax which heaves upwards but does not expand on inspiration. Vocal fremitus is diminished and the percussion note is hyperresonant. In well marked cases it is sometimes impossible to hear the breath sounds because of the coarse sibilant rhonchi. The radiographic appearances are those of pulmonary emphysema. Pousse clinically seems to resemble bysinnosis as described by Fletcher (1949) and Schilling (1950). And like bysinnosis it develops only in those who work in the preparing and carding rooms and seldom or never in those involved in subsequent processes.

Dust control in the preparing and carding rooms of a rope works is very difficult, not only because of the vast amount of dust generated from the great mass of fibres passing at any one time through the carding machines, but because of the size and structure of the machine itself. Some success is being achieved by spraying the bales with water as these are opened, and later by treating the fibres with mineral oil as they pass through the "card". As will be seen from Fig. 1 dust extraction methods are also used, but it is difficult with the present machines to apply suction at all the points of origin of dust. The carding machines are now being re-designed.

\section{Skin Hazards}

In the manufacture of cordage, skin lesions are not uncommon. Ropes which are exposed to water and the weather must be treated with preservatives, and ropes and twines used in agriculture must be protected from insects. Those most commonly used are tar and its derivatives which are applied at an early stage with the result that workers in every section of the industry are exposed. Tar-oil is used to suppress dust in the preparing room, and thus serves a dual purpose. Occasionally some 20 workers out of some hundreds exposed will report within a few days with an acute erythematous rash of the forearm which may within a few days develop into a papular vesicular eruption. Usually the left forearm over which the impregnated

FIG. 2.-Receiving and coiling the slivers. sliver passes is the site affected, but sometimes the legs are also affected. The skin is intensely red, feels hot, is swollen, and on light pressure takes an impression of the finger prints. Severe itching is the rule. These outbreaks are sometimes, but not invariably, associated with the use of a fresh batch of the tar-oil, and occur most commonly not amongst the blondes or brunettes, but amongst sandy-haired workers. The offending batch is withdrawn, and the patients are transferred to other jobs and recover in a few days. Ordinary chemical analysis of dozens of batches has so far failed to reveal anything which can be incriminated as the cause. Calcium oxalate is a natural constituent of all the hard fibres, and occurs in varying amount in crystalline form. An investigation is at present being planned to determine if these outbreaks of acute dermatitis are related to the oxalate content of the raw material.

Oil folliculitis due to the use of mineral oils was formerly very common, and occurred at all stages of manufacture except spinning where the operator has little contact with the treated fibre. The forearms and the outer sides of the lower legs are 
usually affected, as these are the parts mostly in contact with the masses of treated slivers (Fig. 2). The condition was so common that it was usually disregarded in the early stages. Now it is reported early by the fortunately increasing number of girls who are sensitive about their appearance. The condition is well controlled by the provision of facilities for good personal hygiene, by the supply of barrier creams, and if the lesions are established, by the transfer of the affected worker from further exposure until a cure is effected. In days gone by, workers had discovered for themselves that castor oil was useful in preventing these lesions, and they brought their own supply. For 12 years they have been supplied with sulphonated castor oil to apply when cleansing, and the problem is now only minimal

Amongst older women who have worked for years and have accepted the lesions as inevitable, hyperkeratosis occasionally develops. Of the 23 who have come to our notice in 13 years, two have developed malignant changes. The first had a small growth at the site of a hyperkeratotic plaque which on section proved to be a squamous celled epithelioma. Although she gave up her employment, she subsequently developed four other epitheliomata at similar sites on the left forearm during the following four years. The second was a younger woman of 46 whose exposure was slight, but in whom hyperkeratosis was extensive and severe. She also developed an epitheliomatous lesion but further inquiry revealed another possible cause, as her family doctor had been prescribing regularly a mixture of bromides and liq. arsenicalis for more than 20 years.

About 12 men work in the tarring shed. Here boiling tar is decanted into a large metal cylinder. Inside the cylinder is a heavy wire mesh cage into which are placed nets and ropes for treatment. After the materials have been thoroughly impregnated, the tar is allowed to escape into a closed tank and the cage within the cylinder is set in motion. Centrifugal force drives the surplus tar through the meshes into the cylinder, and it drains into the tank. The materials are then hauled out of the cage by lifting gear and transported to the finished product store for packing. The job is unpleasant and dirty and requires no skill. Consequently the turnover of labour is high. This is probably the reason that in 13 years no cases of tar warts or cancers have been seen.

\section{Deafness}

Plaiting is carried out by automatic machines which perform a series of complicated eccentric movements with $\operatorname{cog}$ wheels. As a result the plaiting room is very noisy. The noise is even more intense than that to which a boiler maker is exposed, being of the order of 150 to 200 decibels. The pitch of the note is even higher and more continuous. Fortunately only about 12 workers out of a total labour force of over 3,000 are required to attend the machines in this room. Without exception the older workers have extreme nerve deafness as a result of working in this room, and their condition differs in no way from boiler makers' deafness. Of recent years, replacements of older workers retiring or dying have been recruited only from those already deaf. In the meantime the engineers have been trying to produce a machine which will do the work noiselessly. Because the older workers are already stone deaf and because of our method of recruiting replacements, we have not supplied noise suppressors or such appliances for personal use.

\section{Accidents}

Spinning in the manufacture of cordage in no way differs in principle from textile spinning except that the bobbins are as a rule much larger. Contusions of the fingers and hands, often severe enough to cause fractures, are caused by the swiftly moving flyers. Partial or complete amputations are not infrequently caused by a loop of fine yarn encircling a finger or fingers and tightening rapidly and forcibly. Friction burns are caused by swiftly moving spun yarns and occasionally foreign bodies are driven into fingers. The dropping of heavy bobbins both in the spinning room and in transportation results in many fractured toes. A major problem in the reduction of the accident rate is to persuade girls to use suitably protected footwear, even when this is provided. Incised wounds are frequent, and are caused by the knives used to cut out the strands when the bank of bobbins is full. This type of accident also occurs in the preparing room when bales are being opened (Fig. 1). Scarcely a year passes without a hibernating snake being revealed when the bales are opened in this room. No injuries from this cause have occurred, but there is always a noticeable fall in the rate of work for a few days after such an incident !

The actual making or laying of the ropes may take place in the ropewalk which is over 400 yards long, or it may be done by machinery. The ropewalk is used nowadays only for the "laying " of heavy cables. The process is designed to lay three or more strands in apposition so that the natural tendency of each strand to untwist is counteracted by the tendency of its neighbour to untwist in the opposite direction. No specific hazard occurs here so no description need be given. Longfellow's description is more graphic than we could attempt and is substantially accurate even today. 


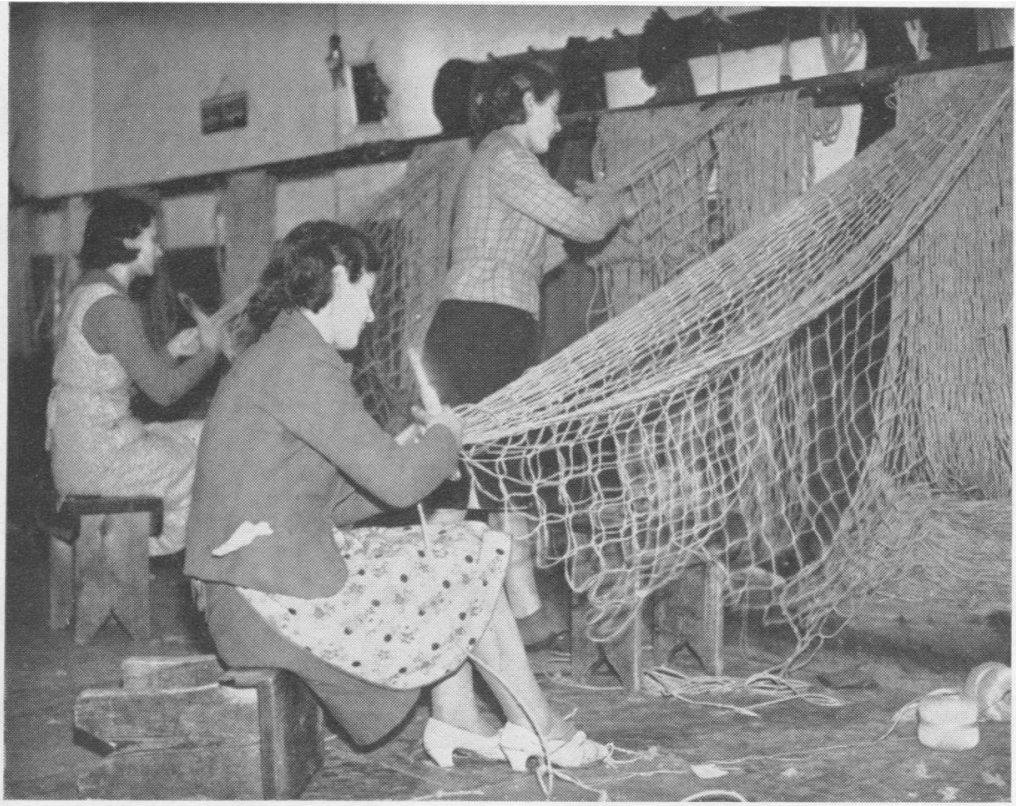

FIG. 3.-Braiders at work.

Tenosynovitis

One of the important products of a rope works is netting, and although simple nets like tennis nets are made, the great bulk of netting is for fishing. The origin of the word net is obscure, but it is said to be related to "knit" or to " neat", for a good net, with all the holes of the same size and shape, is neat. Whatever the derivation, the characteristic of a good net is that the meshes be equal in size and shape and that the knots be tied securely. Attempts have been made since the eighteenth century to invent a machine which could mechanize the process, but success has been only partial. In 1802 the French Government offered a reward of 10,000 francs for a machine to do automatic netting. Jaquard submitted a model, and was summoned to Paris by Napoleon who asked: "Are you the man who pretends to do what God Almighty cannot do-tie a knot in a stretched string?"

A satisfactory machine is now in operation which can make nets rectangular in shape, but the greatest bulk of netting required is not rectangular, and the tailoring of these rectangles to the required shape and size has proved unsatisfactory. As a result about 300 women and girls are still engaged in the ancient craft of braiding. While they work conversation is impossible, as the shape of the net is determined by the number of meshes which each worker must count as she braids. It is impressive to enter a braiding room and see some hundreds of women standing or sitting, facing the wall and working in complete silence. As the net lengthens, in order to maintain tension, the braider sits on a stool, but after further lengthening requires the rearrangement of the net on the steel bar so that the braider is alternately standing or squatting on the stool all day long (Fig. 3). The speed at which braiding is done by experienced workers is very great and varies to some extent according to the material used, but 50 to 70 meshes per minute is not an uncommon rate. The dexterity gained in a series of complicated actions of flexion, extension, pronation, and supination at the wrist joint together with flexion and extension of the fingers, must be seen to be believed. As a result tenosynovitis, or peritendinitis crepitans as Thompson, Plewes, and Shaw (1951) prefer to call it, is common and may be regarded as the occupational hazard of the braider.

The condition seldom or never develops in the trainee worker because speed and efficiency develop together rather slowly. Those affected are women of experience, who for domestic or other reasons have left the industry for a time, and returning, attempt to achieve their former speeds. There is also an increase in the incidence of the condition beginning three to five days after the summer holiday. Here the younger workers are just as susceptible as the older. The hand which holds the needle is the one always affected. Almost any of the extensor tendons may be involved, but those most commonly felt are the brachioradialis (supinator longus), the abductor pollicis longus, the extensor pollicis brevis, and the radial extensors at the wrist.

From January, 1949, until December, 1950, 63 cases were seen, and on only one occasion was a flexor tendon involved. Tenosynovitis was once a serious cause of loss of time. Workers who developed it tended to ignore the condition until it became severe, and at that stage complete immobilization with consequent absence from work was the rule. Unfortunately having left employment and gone outside our control or advice, they remained out, and frequently prolonged complete immobilization resulted in adhesions which further lengthened the period of disability. Further, many patients who had apparently fully recovered, returned to 
work, but within a week were again stricken. For some years now our policy has been to encourage workers to report immediately they feel pain about the wrist joint. The diagnosis is usually easily confirmed by feeling crepitus. The forearm, wrist and fingers we partially immobilize with the wrist hyper-extended and the fingers slightly flexed. This is done by means of an adhesive elastic bandage tightly stretched from the elbow to the finger tips. This strip is fixed by another around the upper forearm and one or two bands over the points at which crepitus is felt. Short wave therapy is given for 10 minutes twice each day, and arrangements are made for the worker to draw her average wage so long as she remains at work. In about a week, passive movements and light massage are begun, followed later by active movements ; the patient is thus encouraged to accept partial but not complete immobilization, for she returns to her job and works slowly. Of the 63 patients already mentioned only one had not completely recovered within 10 days. She recovered in three weeks on being suspended from work, only coming in, with her arm on a sling, for physiotherapy. Usually pain disappears in three or four days, but the treatment is continued for several more and we now have none of the tedious long term cases which were so common some years ago. Our experience seems therefore to coincide with that of Thompson, Plewes, and Shaw (1951).

\section{Summary}

The main processes where hazards occur in the manufacture of cordage, are described. These hazards include a condition which resembles byssinosis, the various skin lesions associated with the use of tar and tar-oils, nerve deafness amongst plaiters similar to boiler maker's deafness, tenosynovitis or peritendenitis crepitans amongst braiders, and various types of accidents.

It is indicated that the industry, because of its history, has been in the past very conservative, but that active steps are now being taken in an attempt to control the various hazards.

I am grateful to my colleagues in the Belfast Ropeworks Ltd., and in particular Mr. A. P. Armstrong and his associates Mr. H. Hodge, Mr. G. Brown, and Mr. W. S. McMeekin not only for information about the processes but also for the historical data about the trade. The knowledge and experience of Sister I. Balmer and of her staff in the Medical Department have been invaluable.

Figs. 1 and 3 were taken by Mr. G. H. Edgar of Messrs. Short Bros. and Harland Ltd., and I am indebted greatly to him for his skill and cooperation. Figure 2 is by the Belfast Telegraph, and I am obliged to the Editor for permission to reproduce it.

\section{REFERENCES}

Fletcher, G. (1949). Proc. 9th Int. Congr. Industr. Med., London, 1948, p. 875. Bristol.

Schilling, R. S. F. (1950). Brit. med. Bull., 7, No. 1-2, p. 52.

Thompson, A. R., Plewes, L. W., and Shaw, E. G. (1951). British Journal of Industrial Medicine, 8, 150 . 